\title{
The Frederic Stanley Kipping Award in Silicon Chemistry
}

\author{
Paul Martin Zelisko
}

Published online: 16 September 2010

(C) Springer Science+Business Media B.V. 2010

In 1960 the Dow Corning Corporation established an award, to be administered by the American Chemical Society (ACS), to recognize the achievement of individuals in the field of silicon chemistry. The award was named the Frederic Stanley Kipping Award in Silicon Chemistry to commemorate the contributions of one of the true pioneers in this field. Since 1976 the Kipping Award has been presented on a biennial basis to an individual who has made distinguished contributions to the field of silicon chemistry or organometallic chemistry of the Group IV elements in the 10 years preceding the nomination, regardless of age or nationality.

\section{Recipients of the Kipping Award}

2010 Yitzhak Apeloig

2008 T. Don Tilley

2006 Akira Sekiguchi

2004 James E. Mark

2002 Kohei Tamao

2000 Peter Jutzi

1998 Joseph B. Lambert

1996 Wataru Ando

1994 Robin Walsh
1992 Nils Wiberg

1990 John L. Speier, Jr.

1988 Raymond Calas

1986 Peter P. Gaspar

1984 Robert J. P. Corriu

1982 Thomas J. Barton

1980 E. A. V. Ebsworth

1978 Hideki Sakurai

1976 Michael F. Lappert

1975 Hans Bock

1974 Hubert Schmidbaur

1973 Adrian G. Brook

1972 Dietmar Seyferth

1971 Alan G. MacDiarmid

1970 Robert West

1969 Robert A. Benkeser

1968 Ulrich Wannagat

1967 Makoto Kumada

1966 Gerhard Fritz

1965 Eugene G. Rochow

1964 Colin Eaborn

1963 Leo H. Sommer

1962 Henry Gilman

P. M. Zelisko $(\bowtie)$

Department of Chemistry and Centre for Biotechnology,

Brock University,

500 Glenridge Avenue,

St. Catharines, Ontario L2S 3A1, Canada

e-mail: pzelisko@brocku.ca 